\title{
College English Culture Teaching from the Perspective of Cross-cultural Communication
}

\author{
Ping Wang \\ Hubei University of Chinese Medicine, Wuhan, Hubei, 430065
}

Keywords: cross-cultural communication; college English culture; teaching strategies

\begin{abstract}
English is the main subject of higher education. Because of the differences between cultures, students inevitably face certain problems in the process of learning English knowledge. Therefore, English culture learning seems particularly important, but from the current college English teaching practice, there are still some defects in the teaching of English culture, which will directly affect the overall quality of college English teaching. From the perspective of cross-cultural communication, this paper deeply analyzes the outstanding problems in the process of college English culture teaching and puts forward corresponding countermeasures to play a positive role in improving the quality of college English culture teaching.
\end{abstract}

\section{Introduction}

With the continuous improvement of the degree of internationalization, the exchanges between countries have become increasingly frequent, so the role of English has become increasingly prominent. The university is the key stage of English learning, and it has a very important impact on students' future employment and development. However, due to the great differences between Chinese and English, students will not learn English in a timely manner if they do not change their cultural perspectives in time. This will cause more problems and affect English learning. . English culture is the content that must be understood in the process of learning English knowledge. In the perspective of cross-cultural communication, strengthening the cultural education of college English has a very positive practical significance for promoting students to better learn and understand English knowledge.

\section{The Outstanding Problems in College English Culture Teaching from the Perspective of Cross-cultural Communication}

\subsection{The insufficient teacher's attention to college English culture teaching}

In the process of student learning, the teacher plays a crucial role in the quality of teaching. It can be said that the level of teacher's teaching is directly related to the degree of students' learning and mastering the course [1]. In the context of curriculum reform, the concept of traditional education and teaching is undergoing tremendous changes. The new concept of curriculum education is gradually integrated into the practice of university education. This is to change the shortcomings of traditional forms of education and improve the overall quality of teaching quality. very important. However, judging from the current college English education practice, there are still some teachers with poor educational quality. Some schools pay less attention to the strength of teachers in the school management process, resulting in insufficient levels of teachers in some schools and therefore accepting and understanding. There are certain deviations in the process of teaching English culture. Because these teachers fail to truly grasp the relationship between English culture and English teaching, it is inevitable that many problems will arise in the process of teaching, and they cannot be implemented. If they fail to take effective measures to improve It will have a greater adverse impact on student learning, affect the student's future growth and development, and restrict the overall quality of students. 


\subsection{The single form of teaching English culture, and students' lack of learning enthusiasm}

All along, due to the influence of traditional education and teaching concepts, indoctrination education runs through the whole process of college English teaching. This is one of the main reasons that influence the quality of college English culture teaching. Infant education has a long history. The main reason is that in the practice of education, the traditional education concept is based on exam-oriented education. In the process of student examinations and progression, the test scores are used as the only evaluation criteria, and parents are evaluating. The quality of school education also emphasizes students' test scores. There are few considerations for other aspects. Under such pressure, schools and teachers have to focus their teaching on the instillation of cultural knowledge on students. The cultivation of all aspects of competence has been ignored [2]. Therefore, in the classroom teaching process, the teacher is the main body of the teaching. The teaching rhythm of the entire classroom is completely controlled by the teacher. The student has always been in a position to passively accept knowledge. In addition, due to the pressure of the current curriculum, the teacher is therefore in the process of teaching. In order to pursue teaching progress, the enthusiasm of students' classrooms is not emphasized in the teaching process. Therefore, the classroom teaching process is not active and the teaching forms are single. Under the perspective of cross-cultural communication, this teaching form obviously cannot meet the actual needs of educational development. It is not a form of teaching that is worth advocating.

\subsection{The lack of effectiveness of English cultural teaching in cross-cultural communication}

With the continuous advancement of curriculum reform, various new forms of teaching have emerged. If these teaching methods can be well applied, they can not only change the defects of the traditional teaching model to some extent, but also improve the quality of teaching. It also has a very important role. From the perspective of cross-cultural communication, in order to keep up with the developmental style of the times and improve the quality of English cultural teaching, teachers also applied these new teaching methods to the teaching process. However, there are still certain problems in the teaching process. 3]. Specifically, because some teachers do not have a deep understanding of cross-cultural communication, they merely stay above the literal meaning and do not comprehend their essence. Therefore, in the process of application, they are simply applied formally, resulting in English. Cultural and cultural innovations are ostensibly superficial and have not played any role in improving the quality of teaching. Sometimes, they also waste a lot of time and cost and reduce the quality of classroom teaching.

\section{The Basic Principles that College English Culture Teaching in Cross-cultural Communication}

\subsection{English culture teaching should have some inspiration}

Due to the adverse influence of traditional teaching methods, teachers are the leading players in the learning process. They lack the enlightenment in the teaching process and instill knowledge into students. They do not give students enough time to think. In the long run, they will The students' learning and growth have a certain negative impact, and students gradually lose their ability to think independently. Therefore, in the perspective of cross-cultural communication, in order to effectively solve this problem, teachers should pay attention to the inspiration of teaching in the teaching of college English culture [4]. In other words, teachers should continue to create opportunities to inspire and guide students in the process of explaining knowledge, mobilize students' enthusiasm for learning, guide students to actively think about problems, and promptly ask their own questions or views and opinions on the issues. During the learning process, students gradually develop independent thinking skills, get rid of dependence on teachers, and develop independent learning habits, laying a good foundation for future learning. 


\subsection{Cultural instruction should be conducted on the premise of conforming to the English syllabus}

In the current educational background, curriculum standards are summarized and refined after a long period of educational practice. They are in line with the overall trend of current education development and the actual learning characteristics of students. They are an important reference for teaching and they are also the goals and main orientations of subject teaching. It is of crucial importance to guide the teaching practice, especially in college English culture teaching. Therefore, in the perspective of cross-cultural communication, teachers should carry out in-depth analysis and study of teaching in the teaching of college English culture on the basis of full compliance with the syllabus, so that within the scope of the curriculum standards, the English culture teaching plan Targeted adjustment, the implementation of learning ability training, so as to maximize the role of cross-cultural communication to play, to achieve the overall improvement of teaching quality [5]. If you do not consider the teaching standards, teaching activities behind closed doors will inevitably deviate from the correct teaching track, and even bring students into the error of learning. This not only wastes classroom teaching resources, but also brings greater disadvantages to students' future learning and development. influences.

\subsection{English culture and education cannot be rushed}

In the process of college English culture teaching, the cultivation of English thinking and cross-cultural communicative competence does not happen overnight. It requires a relatively lengthy process, and in the process requires the reinforcement and guidance of teachers, so as to achieve the intended purpose and achieve Comprehensive improvement of the overall quality of students. Therefore, when cultivating students' intercultural communicative competence in the process of college English culture teaching, teachers should not be rushed, and should be able to effectively guide students and gradually improve their English ability on the basis of students' full understanding of knowledge [6]. In other words, the teacher should focus on solidifying the basic knowledge of the students. For the students' problems in the learning process, the teacher cannot criticize and blame them blindly. Instead, they should help the students identify the root of the problems and solve them in time. This will not only help students Building confidence in learning will, in the long run, help students gradually develop a certain level of learning ability and lay a solid foundation for future study.

\section{The Effective Countermeasures of College English Culture Teaching from the Perspective of Cross-cultural Communication}

Under the traditional teaching model, the college English culture teaching plan is designed and completed independently by teachers. The teachers' perspectives are also adopted. Due to the concept of exam-oriented education, the traditional college English culture teaching plan places too much emphasis on instilling theoretical knowledge. It neglects the training and training of students' intercultural communicative competence, which is very unfavorable to the improvement of students' overall quality [7]. Under the new situation of education development, in order to better meet the basic requirements of quality education and effectively improve the students' comprehensive ability, teachers should re-adjust the teaching plan for college English culture and formulate a relatively clear guidance for the teaching of English culture in universities. Directions to improve students' ability to use English. Specifically, teachers should focus on observing students' learning characteristics and mastery of knowledge in the ordinary teaching process, and then make a comprehensive assessment based on the actual characteristics of the students. On the basis of fully grasping the basic level of the students, the teachers should plan for the previous teaching. Targeted adjustments were made to optimize the contents of college English culture teaching. In line with the requirements of the syllabus, the students' English comprehensive ability was emphasized, and the ability to train and train students' intercultural communication was integrated into the entire process of college English culture teaching. In addition, for the problems found in the teaching process, 
teachers should make dynamic adjustments to the teaching plan, promote the continuous optimization and upgrading of the College English culture teaching program, and provide good prerequisites for promoting the overall improvement of students' overall quality.

For a long time, in the practice of university education, the uniform teaching model has been carried through the entire process of university education. Under the background of curriculum reform, this backward teaching style has been unable to meet the actual needs of educational development, and is more personalized. The education model is the mainstream trend of current education development. Therefore, in the process of college English culture teaching, teachers should promptly abandon outdated teaching ideas, and provide students with targeted teaching plans to help students of different basic levels to improve their English intercultural communicative competence [8]. For students, because the background of growth and the family environment are all different, there will be some differences in the process of accepting new knowledge. Under the unified teaching format, some students may have already understood what they have learned. However, some students still have many problems that have not been solved. Over time, this will cause serious polarization among students, which is not conducive to the smooth implementation of follow-up education. Therefore, the teacher should pay attention to the student's learning situation in the teaching practice. For the students who have a good basic level and accept faster knowledge, they should formulate a teaching plan that is higher than the general level, and expand and extend the knowledge appropriately to broaden the students' knowledge. Face-to-face, and for students with poor basic level and accepting new knowledge, the teacher should appropriately reduce the difficulty of the course and give students more basic knowledge to help students to lay a solid foundation in English. In this way, students of different basic levels can improve themselves in the teaching process, so that they can truly implement their own teaching according to their aptitude.

For most students, the interest in knowledge is a key factor affecting the degree of acceptance and understanding. Therefore, in order to effectively improve the quality of college English culture teaching, to develop students' intercultural communicative competence, it is very important to focus on improving the interest of teaching. This is also a key factor affecting the quality of teaching [9]. In the process of traditional college English culture teaching, because of the teacher's heavy curriculum pressure and the adverse influence of traditional teaching evaluation methods, the teacher will focus on the knowledge and indoctrination of the knowledge in the teaching process. Sex attention is generally less. Under such a teaching model, it is very difficult to improve the quality of teaching. Therefore, in the perspective of cross-cultural communication, teachers should pay attention to the interest of teaching, and actively adopt effective methods to improve the teaching of the fun, so as to achieve the improvement of teaching quality.

\section{Conclusion}

In summary, under the perspective of cross-cultural communication, there are still certain problems in the process of college English culture teaching. Teachers should actively innovate and improve teaching strategies to stimulate students' interest in English learning, and optimize the College English culture teaching program from the perspective of cross-cultural communication. , Continuously improve the students' English communication skills and promote the continuous improvement of the quality of college English culture teaching.

\section{References}

[1] Qiu Xiaofen. Construction of College English Culture and Education System in the Context of Cross-cultural Communication[J]. Overseas English (below), 2017(4):153-155.

[2] Lin Na. Take the tea culture as an example to practice "flipping classroom" in college English culture teaching [J]. Fujian tea, 2017 (12): 200-201.

[3] Tan Jing. Penetration of Chinese and Western Tea Culture Differences in College English Culture Teaching[J]. Fujian Tea, 2017(8):171-172. 
[4] Gao Mengying. The influence of English culture teaching on intercultural communication ability of middle school students[J]. Shenzhou, 2018(5):62-63.

[5] Qiu Xiaofen. Construction of College English Culture and Education System in the Context of Intercultural Communication [J]. Overseas English (I), 2017 (4): 405-407.

[6] Cheng Sumin.Analysis of English Cultural Teaching in the Perspective of Intercultural Communication[J]. Science and education,2016(8):162-164.

[7] Zhou Miao. On the Cultural Education and Reform of College English from the Perspective of Intercultural Communication [J]. Reading and Writing (mid-term), 2016(2):20.

[8] Peng Xinzhu. Current status of college English culture teaching and teaching management [J]. Journal of Jilin Provincial Institute of Education, 2016(12): 62-64.

[9] Xu Chengsheng. Ecological imbalance in college English teaching and its suggestions [J]. Campus English (late), 2015(7):20-21. 